\title{
Covid19 autopsy in Oklahoma detects the facultatively anaerobic Proteus mirabilis in lungs - reason of death written as "complications of hepatic cirrhosis" with renal nephrosclerosis and acute bronchopneumonia - all symptoms associated with Proteus mirabilis
}

Sandeep Chakraborty

\section{Letter}

The hypothesis of SARS-Cov2 enabling anaerobic bacteria colonize the lungs in Covid19 is based on sequencing data from several studies across the globe [1]. Here, the autopsy of a 42-year-old obese man with muscular dystrophy shows [2] the presence of Proteus mirabilis in the lungs (found by culturing), a facultatively anaerobic bacteria that is often implicated in the reasons cited for the cause of death.

\section{Autopsy results}

1. nasopharyngeal swabs were positive for SARS-Cov2

2. lung parenchymal swabs were negative for SARS-Cov2

3. 'No viral inclusions, mucus plugging in airways, eosinophils, or myocarditis'.

4. 'lungs revealed foci of acute bronchopneumonia'.

5. 'liver cirrhosis'

6. 'renal nephrosclerosis, tubular fan-shaped crystals (kidneys)'

7. 'cause of death was listed as "complications of hepatic cirrhosis",

\section{Bacteria cultured - and not all bacteria culture well - were classified as nontoxi- genic}

They reported that aerobic/anaerobic cultures of the lung tissue grew 'nontoxigenic Escherichia coli, Candida tropicalis, and Proteus mirabilis.' [2]. However, the facultatively anaerobic Proteus mirabilis is implicated in several of the reasons responsible for the death of the patient.

\section{Kidney}

Urease is an important virulence factor for Proteus mirabilis. It hydrolyzes urea, leading to stone formation [3]. Within the stones, 'COM crystals are arranged radially into fan-shaped profiles with distinct concentric laminations' [4] (see autopsy results). Proteus mirabilis has unique kidney pathology, and is an unique species that causes a large number of kidney stone formation, and greater kidney damage in rats than other similar bacteria with urease enzymes [5].

\section{Liver}

Patients with cirrhosis have a higher proportion of Proteus species compared with control,their presence in the gut are known to contribute to the pathogenesis of hepatic encephalopathy by breaking down urea into ammonia and carbonic acid [6] 


\section{Pneumonia}

Proteus mirabilis is not associated with pneumonia very often. However, 13 patients with Proteus mirabilis pneumonia in Japan showed resistance for levofloxacin [7], while extended-spectrum $\beta$-Lactamase producing Proteus mirabilis was implicated in pneumonia in Korea [8].

\section{Proteus mirabilis grows in anaerobic conditions}

Nutrients (iron, zinc, amino acids, and dioxygen) are important for the growth and swarming behavior of Proteus mirabilis [9]. Also, anaerobic respiration uses a 'complete oxidative TCA cycle' that drives multicellular swarming [10]. Proteus mirabilis swarming growth is the development of concentric rings of growth, producing a bull's-eye colony [11].

\section{Role of hemolysin in Proteus mirabilis}

The calcium-independent hemolysin HpmA [12] seems to be the primary virulence factor responsible for cytotoxicity to human renal proximal tubular epithelial cells (a protective barrier for the kidney) [5] HpmA damages kidney tissues [13].

\section{Conclusion:}

The detection of the facultatively anaerobic Proteus mirabilis during the autopsy of a patient must be considered more seriously as a causative agent of mortality since it is implicated in all of the reported maladies, especially in the kidneys.

\section{References}

1. Chakraborty S (2020). Sars-cov2 enables anaerobic bacteria (prevotella, et al) to colonize the lungs disrupting homeostasis - symptoms (ards, septic shock, blood clots, arterial stroke) finds resonance, with key differences, in the 'forgotten disease' lemierre syndrome, caused by anaerobic bacteria enabled by epstein barr virus. doi:10.31219/osf.io/usztn. URL osf .io/usztn.

2. Barton LM, Duval EJ, Stroberg E, Ghosh S, Mukhopadhyay S (2020) Covid-19 autopsies, oklahoma, usa. American Journal of Clinical Pathology .

3. Jones B, Mobley H (1988) Proteus mirabilis urease: genetic organization, regulation, and expression of structural genes. Journal of bacteriology 170: 3342-3349.

4. Khan SR, Pearle MS, Robertson WG, Gambaro G, Canales BK, et al. (2016) Kidney stones. Nature Reviews Disease Primers 2: 1-23.

5. Armbruster CE, Mobley HL, Pearson MM (2018) Pathogenesis of proteus mirabilis infection. EcoSal Plus 8 .

6. Hamilton AL, Kamm MA, Ng SC, Morrison M (2018) Proteus spp. as putative gastrointestinal pathogens. Clinical microbiology reviews 31: e00085-17.

7. Okimoto N, Hayashi T, Ishiga M, Nanba F, Kishimoto M, et al. (2010) Clinical features of proteus mirabilis pneumonia. Journal of infection and chemotherapy 16: 364-366.

8. Ryou SH, Bae JW, Baek HJ, Lee DH, Lee SW, et al. (2015) Pulmonary pneumatocele in a pneumonia patient infected with extended-spectrum $\beta$-lactamase producing proteus mirabilis. Tuberculosis and respiratory diseases 78: 371-374. 
9. Wilkerson ML, Niederhoffer EC (1995) Swarming characteristics of proteus mirabilis under anaerobic and aerobic conditions. Anaerobe 1: 345-350.

10. Alteri CJ, Himpsl SD, Engstrom MD, Mobley HL (2012) Anaerobic respiration using a complete oxidative tca cycle drives multicellular swarming in proteus mirabilis. MBio 3: e00365-12.

11. Belas R, Schneider R, Melch M (1998) Characterization of proteus mirabilisprecocious swarming mutants: Identification of rsba, encoding a regulator of swarming behavior. Journal of bacteriology 180: $6126-6139$.

12. Mobley Há, Chippendale G, Swihart K, Welch R (1991) Cytotoxicity of the hpma hemolysin and urease of proteus mirabilis and proteus vulgaris against cultured human renal proximal tubular epithelial cells. Infection and immunity 59: 2036-2042.

13. Cestari SE, Ludovico MS, Martins FH, da Rocha SPD, Elias WP, et al. (2013) Molecular detection of hpma and hlya hemolysin of uropathogenic proteus mirabilis. Current microbiology 67: 703-707. 